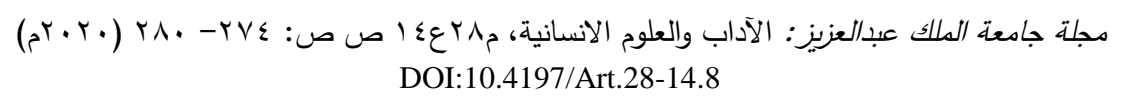

وادي المشقر في المجمعة: دراسة مورفومترية بإستخدام نموذج الارتفاعات الرقمي

$$
\text { حمد بن أحمد التويجري }
$$

استاذ مشارك قسم الجغرافيا كلية الاد/ب جامعة الملك سعود

فرحان بن حسين الجعيدي

استاذ مشارك قسم الجغرافيا كلية الاداب جامعة الملك سعود

$$
\text { منيره ابراهيم الخوفي }
$$

دراسات عليا قسم الجغرفيا كلية الاداب جامعة الملك سعود

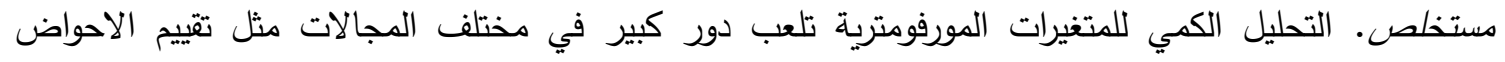
النهرية والجافة وادارة المياة. وتهدف هذة الدراسة الى تحديد المتغيرات المورفومترية لحوض وادي المشقر وهو أحد أهم أودية منطقة الرياض والواقع في مدينة المجمعة شمال العاصمة. وحيث ان المجمعة تتعرض لامطار سنوية اتت اهمية دراسة الوادي الذي يمر في قلب مدينة المجمعة ويلتقي بوادي الكلبي هناك. . وقد إعتمدت هذة الدراسة في منهجيتها على بينات الارتفاعات الرقمية DEM لإستخلاص الخصائص المورفومترية وتحليلها باستخدام نظم

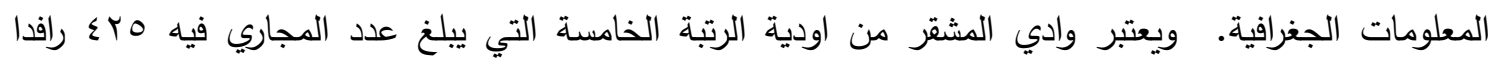
وبمجموع أطوال تقدر بـ VY ك كم. وتثير نتائج الدراسة الى محدودية تأثير السيول على المنطقة العمرانية في مدينة

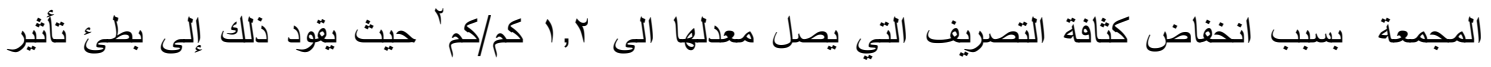
السيول.

الكلمات المفتاحية: وادي المشقر، المجمعة، التحليل المورفومتري، نموذج الارتفاعات الرقمي، نظم المعلومات

الجغرافية

للطرق والبنية التحتية في المناطق الحضرية والزراعية. وبالتالي أصبحت المساحة التي تحتلها أنظمة التصريف لهذه الأودية مجالاً واسعاً للدراسات

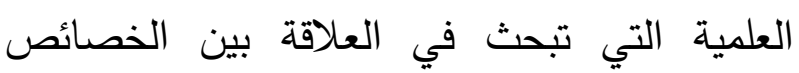
المورفومترية والخصائص الهيدرولوجية على مدى لبح

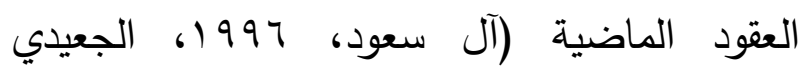

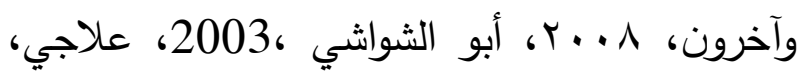

\section{المقدمة}

تمثل الأودية أحد أهم مصادر المياه والأماكن الخصبة التي إتخذها الانسان مكاناً لاقامة القرى التاديه الزراعية في المناطق الجافة منذ القدم. ومع التوسع التحان الحديث للمدن في المملكة العربية السعودية تزايد الإهتمام بدراسة هذه الأودية التي أصبحت مصدراً للمشاكل البيئية نتيجةً لما تحدثه السيول من تدمير لإودية لإني 
أخطار السيول عن هذه المدينة في بناء عدد من

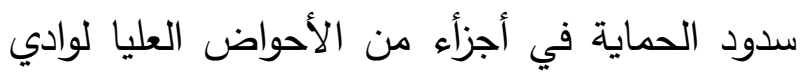
المشقر • وحيث أن لحجز المياه في هذه السدود آثاره

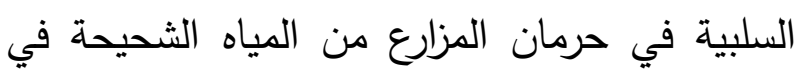
هذه المنطقة الصحراوية. وحيث تحتاج الدراسات الهيدرولوجية والهندسية توفير بيانات علمية عن

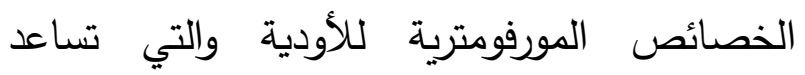
المهندسين على إبتكار الحلول الهندسية بدقة وأمان وكفاءة عالية في حل مثل هذه المشكلات البيئية فإن هذه الدراسة تهدف إلى إستخدام نموذج الارتفاعات الرقمية عالية الوضوح المكاني لإستخلاص وتحليل الخصائص المورفومترية لوادي المشقر في المجمعة.

منطقة الدراسة

تقع منطقة الدراسة في شمال مدينة الرياض بين

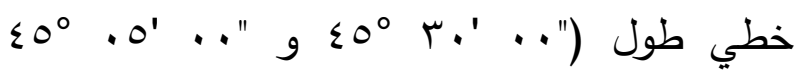

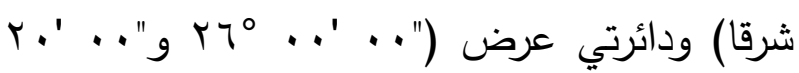
roº

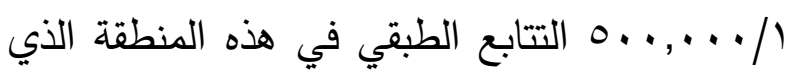
يأتي من الأقدم للاحدث كما يلي: تكوينات طويق،

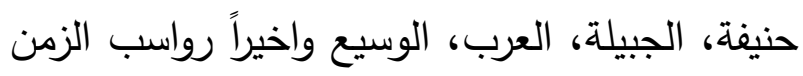
الرباعي. حيث تسيطر صخور تكوينات العصر الجوراسي المتوسط على معظم جيولوجية المجمعة.

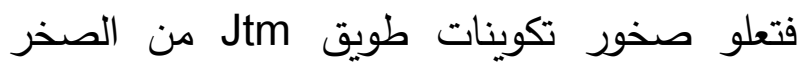
الجيري المتكاثف والمارل والكلكارنايت بقية صخور

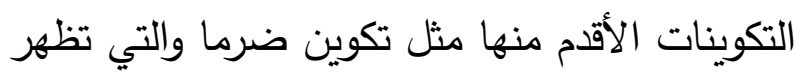

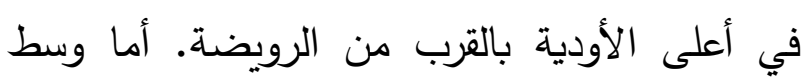

2010 ؛ الصالح، 9991). فالحوض المائي مورفومترياً يمثل وحدة مساحية يمكن قياسها كمياً

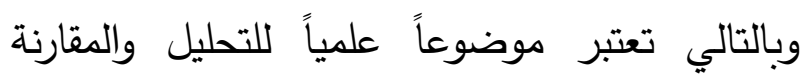
والتصنيف والتي يحتاجها صانع القرار في إدارة هذه الأحواض لضمان الاستدامة في استخدامها كمصادر

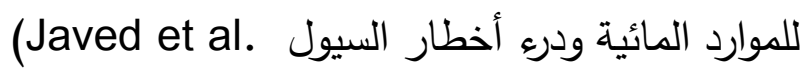
.2009; Prakash et al. 2019) وفي الآونة الأخيرة أحدثت التطورات الهائلة في تتابع تدفق بيانات الإستشعار عن بعد نقلة نوعية في الإدان

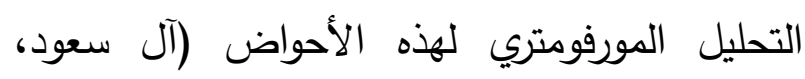

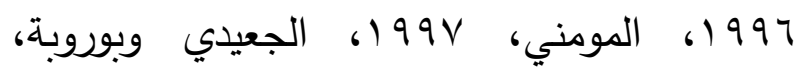

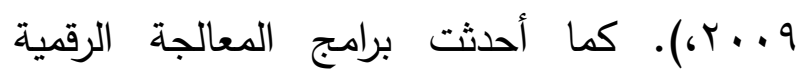
المتقدمة في نظم المعلومات الجغرافية إمكانية تحليل

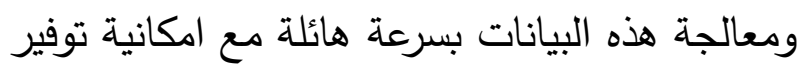
الوقت والجها والتكلفة المادية (التويجري وآخرون، 9 1 (r). ولذلك لا يكاد تخلو دراسة علمية للأودية من التحليل المورفومتري الذي يعتمد على البيانات التي يتم اشتقاقها من نموذج الارتفاع الرقمي

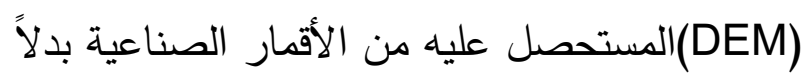
من الخرائط الكنتورية. حيث يتم استخلاص شبكة المجاري المائية والعلاقات بين الرتب النهرية ومحيط لهن لهن

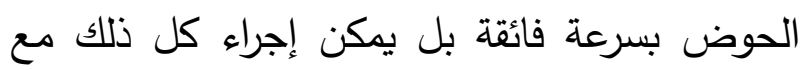
محاكاه هيدرولوجية لجريان السيول. وحيث أن مدينة المجمعة من المدن التي تتعرض لهن لأخطار السيول في مواسم الامطار بشكل مستمر فقد إرتكزت الحلول الهندسية التي طرحت سابقاً لدرو لادئ 
الوادي فتسيطر عليه صخور العصر الجوراسي ومن الناحية الجيومورفولوجية تسيطر على المنطقة الأدنى لتكوين حنيفة Jh الذي يتألف من الحجر الطبيعة التضاريسية المنخفضة التي تقطعها عدد من

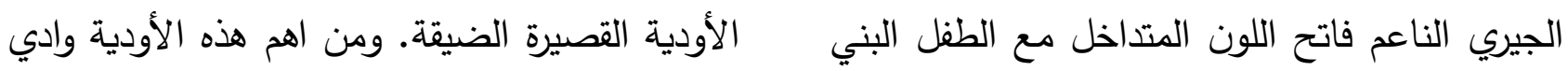

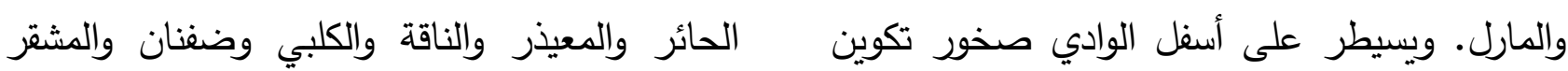

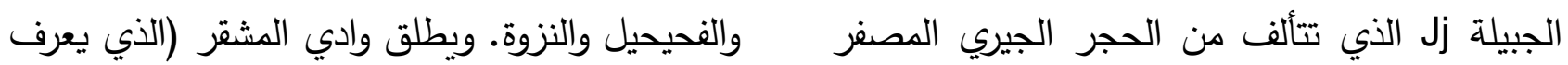

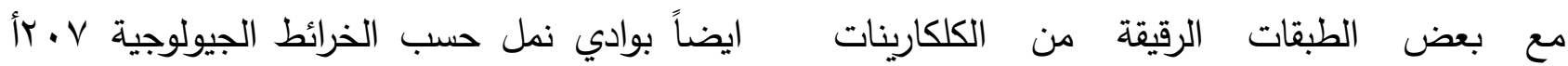
والدولومايت المتماسك. كذلك يظهر في اسفل الوادي عام 1901 (م) على الوادي الذي ينحدر من ظهرة

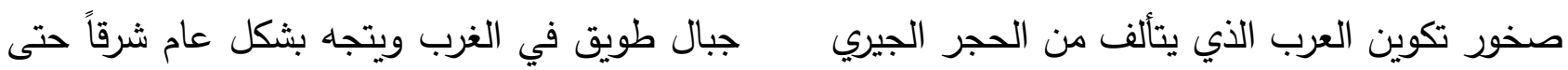
البني اللون والبريشا. كما تظهر ايضاً صخور تكوين يلتقي مع وادي الكلبي في المجمعة. الوسيع من الحجر الرملي بالقرب من مفيض الوادي.

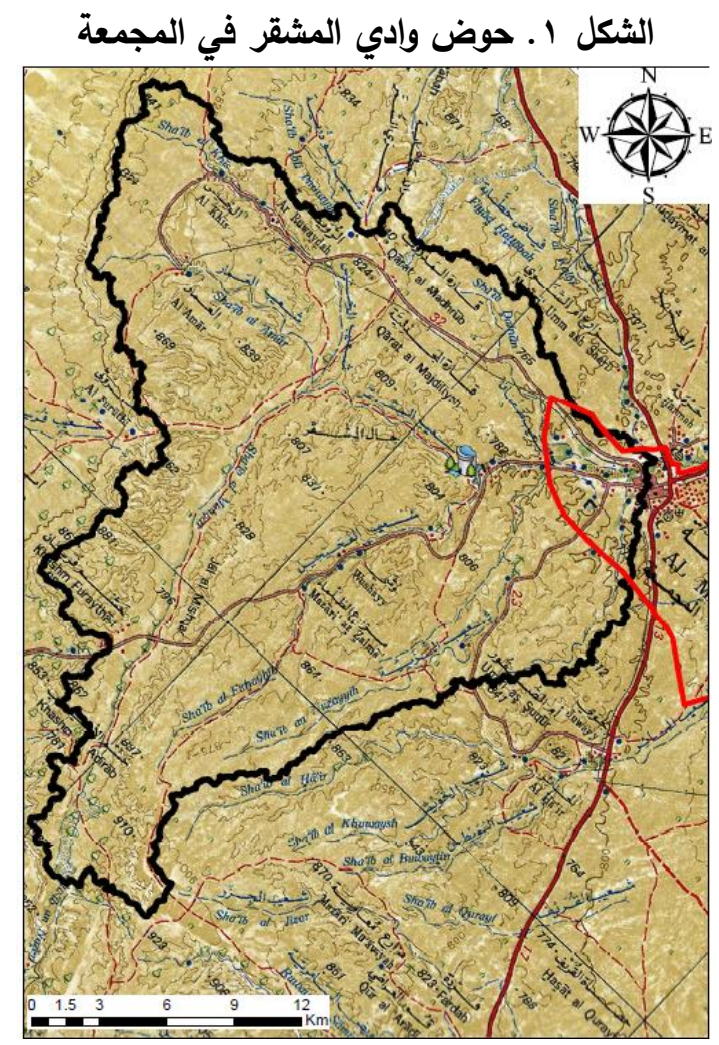

تستخدم نموذج الارتفاعات الرقمية التي تم الحصول منهجية الاراسة:

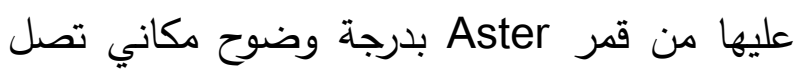

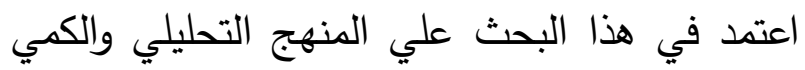
المطبق في مثل هذا النوع من الابحاث حيث إلي • بام. فقد تم انشاء حوض وادي المشقر والرتب 
التحليلات المتعلقة بالمتغيرات المورفومترية لحوض وادي المشقر كما هو موضتح في الجدول (1):
المائية للوادي والاودية المجاورة عبر إستخلاص نقطة الإلتقاء مع وادي الكلبي الواقعة غرب مدينة المجمعة. وقد تم استخدام المنهج الكمي لإجراء

جدول رقم (1)

المتغيرات المورفومترية

\begin{tabular}{|c|c|c|c|c|}
\hline 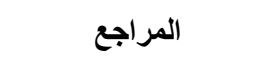 & 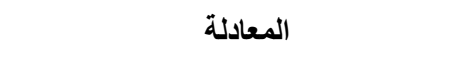 & & المتغيرات المورفومترية & J \\
\hline Schumm (1956) & GIS software - Raster Calculator & $(\mathrm{P})$ & محيط الحوض Basin Perimeter & \multirow{7}{*}{ 武。 } \\
\hline Schumm (1956) & GIS software - Raster Calculator & (A) & Basin Area مساحة الحوض & \\
\hline Schumm (1956) & GIS software - Raster Calculator & (Lb) & Basin Length طول الحوض & \\
\hline Schumm (1956) & $\mathrm{BW}=\mathrm{A} / \mathrm{Lb}$ & $(\mathrm{Wb})$ & عرض الحوض Basin Width & \\
\hline Horton (1932) & $\mathrm{Ff}=\mathrm{A} / \mathrm{Lb}^{2}$ & (Rf) & معامل شكل الحوض Form Factor & \\
\hline Strahler (1964) & $\mathrm{Rc}=4 * 3.14 * \mathrm{~A} / \mathrm{P}^{2}$ & $(\mathrm{Rc})$ & نسبة استدارة الحوض Circularity ratio & \\
\hline Schumm (1956) & $\operatorname{Re}=(2 \sqrt{(\mathrm{A} / \pi)}) / \mathrm{Lb}$ & $(\mathrm{Re})$ & نlongation ratio نسبة الاستطالة & \\
\hline Schumm (1956) & GIS software - Raster Calculator & $(\mathbf{Z})$ & الارتفاع الأقصى Maximum Elevation & \multirow{5}{*}{ 司 } \\
\hline Schumm (1956) & GIS software - Raster Calculator & $(\mathrm{z})$ & الارتفاع الأدنى Minimum Elevation & \\
\hline Burrough (1986) & GIS software - Raster Calculator & $(\mathrm{S})$ & درجة الانحدار للحوض Degree of Slope & \\
\hline Strahler (1957) & $\mathrm{R}=\mathbf{Z}-\mathrm{Z}$ & $(\mathrm{R})$ & Relief التضرس & \\
\hline Schumm (1956) & $\mathrm{Rr}=\mathrm{R} / \mathrm{Lb}$ & $(\mathrm{Rr})$ & Relief ratio التضاريس النسبية & \\
\hline Strahler (1957) & Hierarchial rank & $(\mathrm{U})$ & رتب المجاري Stream Order & \\
\hline Horton (1945) & $\mathrm{Nu}=\mathrm{N} 1+\mathrm{N} 2+\ldots+\mathrm{Nn}$ & $(\mathrm{Nu})$ & عدد المجاري حسب الرتبة Stream numbers & \\
\hline Horton (1945) & Length of the stream & $(\mathrm{Lu})$ & طول الرتب Stream length & \\
\hline Horton (1945) & Lur $=\mathrm{Lu} /(\mathrm{Lu}-1)$ & (Lur) & Stream length ratio معدل طول الرتب & \multirow[t]{2}{*}{ 寻 } \\
\hline Strahler (1964) & $\mathrm{Rb}=\mathrm{Nu} / \mathrm{Nu}+1$ & $(\mathrm{Rb})$ & نسبة التشعب مifurcation ratio & \\
\hline Horton (1932) & $\mathrm{Dd}=\mathrm{Lu} / \mathrm{A}$ & $(\mathrm{Dd})$ & كثافة التصريف Drainage density & \multirow{4}{*}{$\begin{array}{l}\frac{j}{3} \\
\frac{3}{3} \\
. \overline{3}\end{array}$} \\
\hline Horton (1932) & $\mathrm{Fs}=\mathrm{Nu} / \mathrm{A}$ & $(\mathrm{Fs})$ & تكرار الرتب Stream Frequency & \\
\hline Smith (1950) & $\mathrm{T}=\mathrm{Dd} * \mathrm{Fs}$ & $(\mathrm{T})$ & نسيج التصريف Drainage texture & \\
\hline Horton (1945) & $\mathrm{Lo}=1 / \mathrm{Dd} * 2$ & (Lo) & $\begin{array}{r}\text { flow of overland } \\
\text { flow التدفق الارضي } \\
\end{array}$ & \\
\hline
\end{tabular}

الزمنية اللازمة لوصولها الى الوادي الرئيسي. لذلك التحليل والمناقشة تساهم الخصائص الشكلية في تحديد درجة الخطورة الخصائص الثكلية: تمثل اشكال الاحواض في انتظامها واقترابها من على المدن والظواهر البشرية الأخرى (خضر،1997 الاشكال الهندسية المعروفة الدائرة والمستطيل فراج،2012). ويوضح الجدول رقم (Y) نتائج قياس المتغيرات الشكلية لحوض وادي بطحان على النحو والمثلث مؤشراً على نوعية التكوين الصخري للحوض الص وبالتالي تؤثر في عملية تجميع مياه الجريان والمدة التالي: 
جدول رقم (r) (r)

نتائج قياس المتغيرات الهندسية لحوض وادي المشقر

\begin{tabular}{|c|c|c|c|c|c|c|}
\hline نسبة الاستطالة & معامل استدارة & معامل شكل & عرض الحوض & طول الحوض & مساحة الحوض كم” & محيط الحوض \\
\hline$\cdot, \Lambda$ & $\cdot, Y$ Y & $\cdot, 0$ & 16.7 & 31 & 519 & 157.8 \\
\hline
\end{tabular}

استخراج مساحة الحوض باستخدام نظم المعلومات

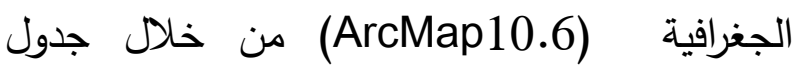

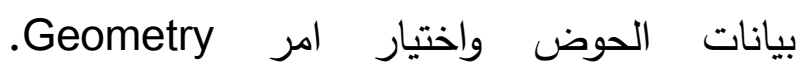
Calculator $.519 \mathrm{Km}^{2}$ - طول الحوض Basin Length ورمزه (Lb) ويحسب بالكيلومتر او بالمتر · و يقصد به المسافة

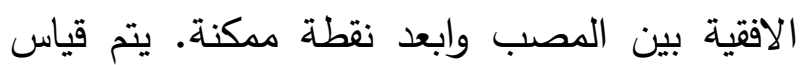
طول الحوض باستخدام نظم المعلومات الجغرافية

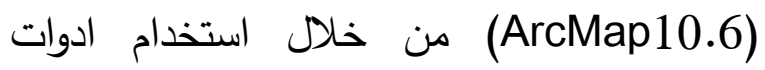
القياس. حيث بلغ طول حوض وادي المشقر 31 Km ويتم الاعتماد على هذا المقياس في قياس العديد من الخصائص المورفومترية، ويؤثر أيضا على سرعة الجريان والتسرب والتبخر والنتح حيث يتاسبون مع الحوض تتاسب طرديا (علاجي،2010 ; سلوم،2012) أي كلما زاد الطول زادت نسبة التبخر

$$
\text { والتسرب والنتح. }
$$

- عرض الحوض Basin Width ورمزه (Wb) ويحسب بالكيلومتر أو بالمتر . عرض الحوض علرض يقاس بطريقتين اما بأبعد مسافة بين نقطتين بعرض بالبر برض

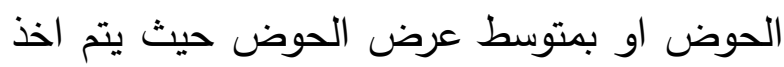

- محيط الحوض (Basin Perimeter): الذي يأخذ رمز (P) و هو خط وهمي في الحقيقة يصل بين قمم المرتفعات التي عندها يقسم المياه ما بين الحوض و ما يجاوره من احواض أخرى والذي ما لمان يسمى بخط تقسيم المياه أي حدود الحوض لهض (خضر (Hajam et al .2013) : 1997) يستخدم في تحديد شكل الحوض ويتم حساب محيط الحوض بالاعتماد علي نموذج الارتفاعات الرقمية ومن خلال اداءة الحاسبة الهندسية "Calculate Geometry" في برنامج (ArcMap10.6) لنظم المعلومات الجغرافية في جدول بيانات الحوض ولقد بلغ محيط

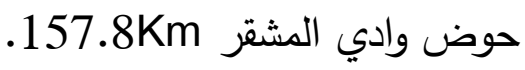

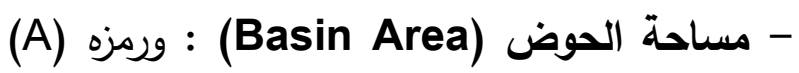
هناك علاقة طردية بين مساحة الحوض وكمية الفواقد أي كلما كبرت مساحة الحوض كلما زادت فيها الفواقد والتسربات وتأخذ زمن تصريف أكثر

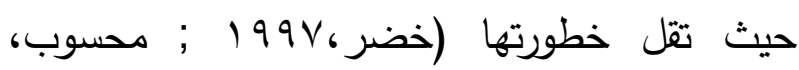

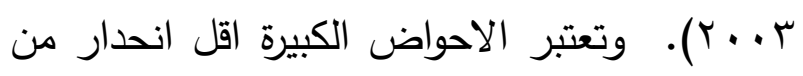

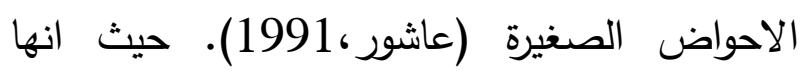

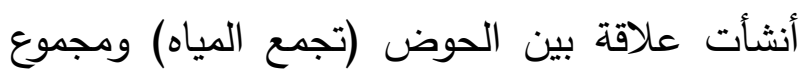
طول الرتب (2015. Dubey et al ) ويمكن 
اكثر تعرجا فتعتبر المساحة الحوضية في بداية Magesh et al ) دورتها التحتية أي بمرحلة الثباب 2011). وقد بلغت قيمة معامل الاستدارة لحوض

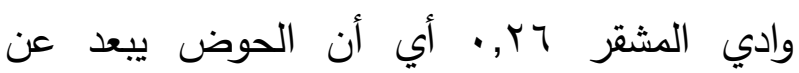
الاستدارة ويكون الحوض غير منتظم الأجزاء وممت ويقل بالتالي تأثيره على التدفق. - نسبة الاستطالة Elongation ratio ورمزه و هو مؤشر هام في تحليل شكل الحوض حتى يساعد في إعطاء فكرة عن طابع كيفية وصول Hajam et al ) المياه الجارية الى المصب لمبك 2013.) فكلما اقتربت النتيجة من واحد صحيح فانها تشير الى تضرس منخفض للغاية الى (Magesh)

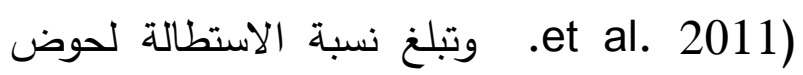
وادي المشقر ^,، وهذا يدل على وجود تضرس منخفض وبالتالي يميل الحوض الى قلة التصريف ولايشكل خطورة تذكر على المنطقة العمرانية. الخصائص التضاريسية: تكمن أهمية دراسة الخصائص التضاريسية حيث تعبر عن انعكاسا لزيادة فعالية عوامل التعرية داخل حدود الحوض ويعطي مدلولا أيضا على أنواع الصخور الموجودة فيه (علاجي، 2010)، ويمكن تحديد الدورة العمرية بالنسبة لتعرية (أبوالشواشي،2003) ويمكن معرفة العوامل التي أثرت في تكوين هذا الحوض و تفسير خصائصه المساحية و خصائص شبكة المياه (فراج، 2012) و يمكن ايضا معرفة معدل سرعة الجريان حيث كلما
أكثر من نقطة على عرض الحوض لثلاث مسافات حقيقة واخذ منها المتوسط (خضر، 1997). يبلغ عرض حوض وادي المشقر 16.7كم وهو مايقارب نصف طول الحوض. ويستخدم قياس عرض الحوض كامؤشر لتحديد حجم أخطار السيول لتأثيره علي حجم التصريف. - معامل شكل الحوض Form Factor ورمزه وهوعلاقة بين طول الحوض وعرضنه وهو (Ff) مؤشر يدل علي تتاسق الحوض في شكله. كلما اقترب معامل شكل الحوض الى صفر دل علي عدم تتاسق الحوض وعدم انتظامه (محسوب، r...... واذا اقترب من رقم ا دل علي اتخاذ الحوض شكلا دائريا ممايؤدي لسرعة تحويل مياه الأمطار إلي مياه سيول. ولقد بلغ معامل الشكل في حوض وادي المشقر 0, • اي ان سرعة تحويل مياة الامطار الى سيول تعتبر متوسطة.

Basin نسبة استدارة الحوض المائي Circularity ratio ورمزه (Rc) وتستخدم لوصف الحوض واقتراب شكله او ابتعاده من شكل الدائرة (فراج، 2012). فكلما اقترب الرقم من واحد صحيح يميل الشكل الي الاستدارة وبالتالي يدل على قدرة الحوض في تجميع كمية المياه من كل الروافد في وقت واحد ويصبح وصولها دفعه واحده الي الوادي الرئيسي مما يمثل خطورة أكبر على المناطق الواقعة في اسفله (خضر،1997 ; سلوم،2012 ;ريان،2014)، و كلما ابتعد الرقم من واحد اصبح 
زادت نسبة التضرس كلما زادت سرعة الجريان مما حمل الرواسب معها وتدمر كل ما يعترضها

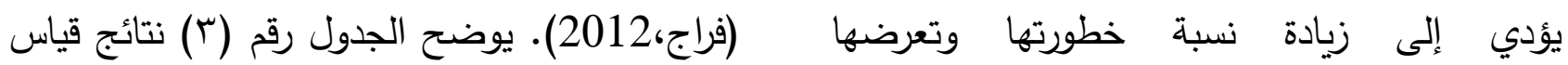
للسيول،(فراج، Magesh et al .2011; 2012 ) الخصائص الثكلية لحوض وادي الششقر على النحو حيث تصرف المياه في وقت قصير مما يؤدي الى التالي: جدول رقم (r)

نتائج الخصائص التضاريسية لحوض وادي المشقر

\begin{tabular}{|c|c|c|c|c|}
\hline التضاريس النسبية & التضرس م & درجة الانحدار للحوض & أدنى ارتفاع م & أقصى ارتفاع م \\
\hline 0.007 & YII & r $\Upsilon^{\circ}-0^{\mathrm{O}}$ & $V \cdot \lambda$ & 919 \\
\hline
\end{tabular}

الجبلية (Hajam et al (2013) ولقد بلغت اعلى ارتفاع بوادي المشقر 9 الو مترا. وأدنى ارتفاع بلغ 708 وهو ما يمثل نقطة المصب كما في الجدول (r) (r). ويوضح شكل رقم (Y) مناسيب الارتفاعات

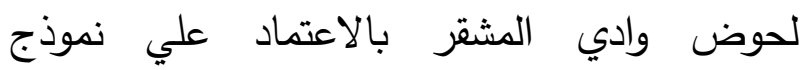

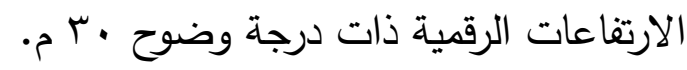
الثكل ץ. الارتفاعات لحوض وادي المشقر بلإعتماد على نموذج الارتفاعات الرقمية

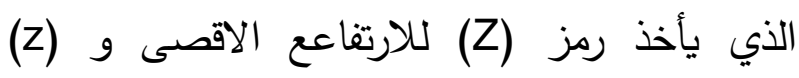
للارتفاع الادنى حيث ان الارتفاع الاقصى والادنى الآنى

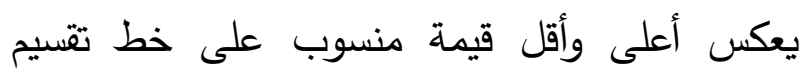
المياة. وتساهم على استتباط التضرس والتضاريس النسبية ودرجة الانحدار، حيث تدل أدني قيمة الي المناطق السهلية واعلى قيمة تدل الي الدناطق 


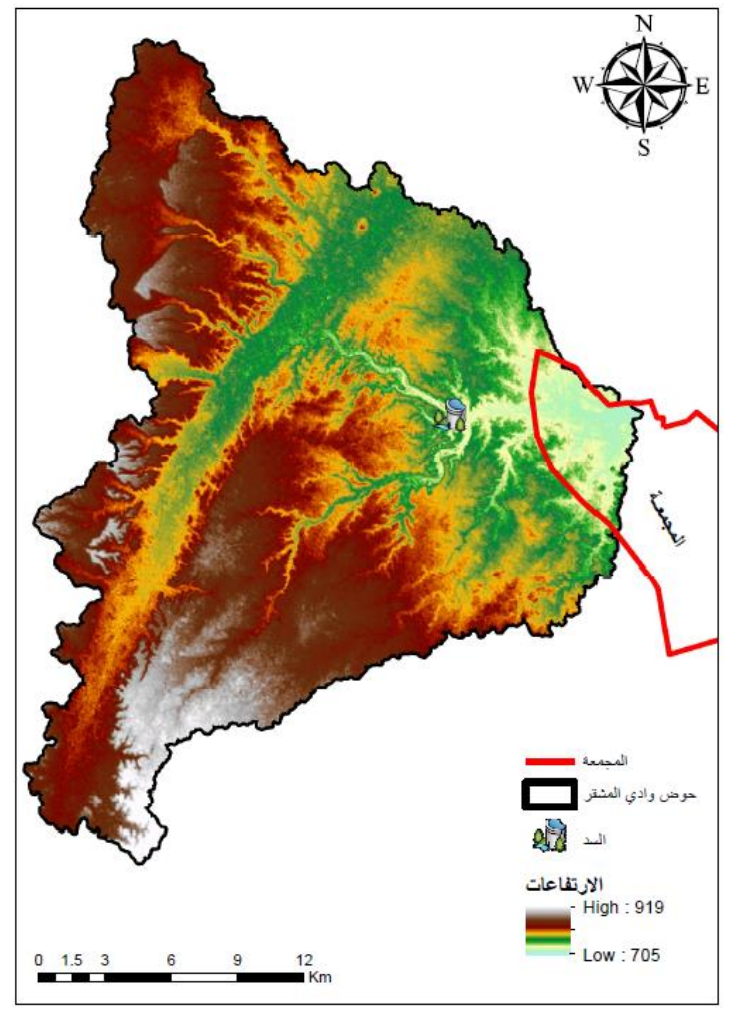

- درجة الانحدار "الميول" للحوض ( Degree of ميتم إجراءها على نموذج الارتفاعات الرقمية ضمن

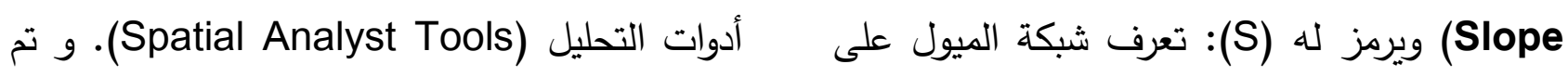

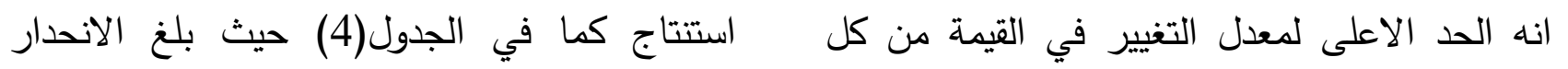

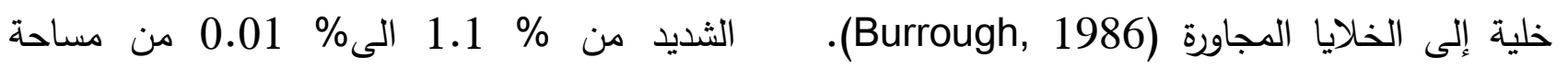
حيث أن عملية الجريان لأتحدث بشكل منتظم فوق الحوض حيث انها مساحة قليلة جدا ،وبلغت نسبة

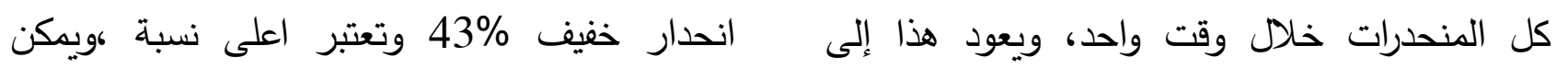

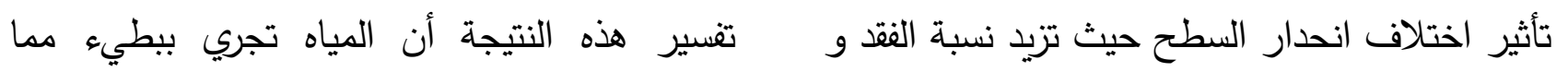

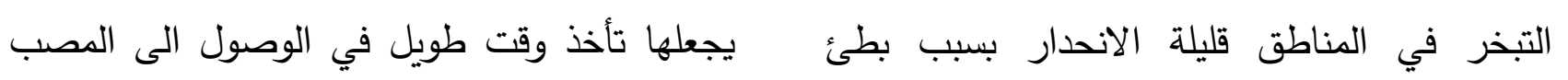

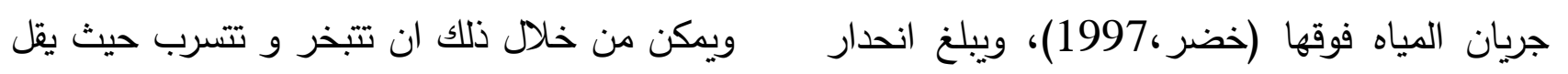

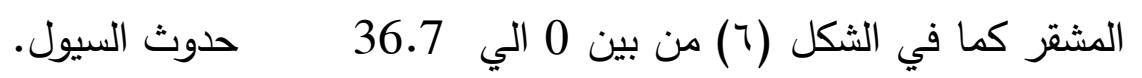
وتبعا لتصنيف بونج (Young, 1972, p.173) الثكل r. درجة الإنحدار لحوض وادي المشقر 


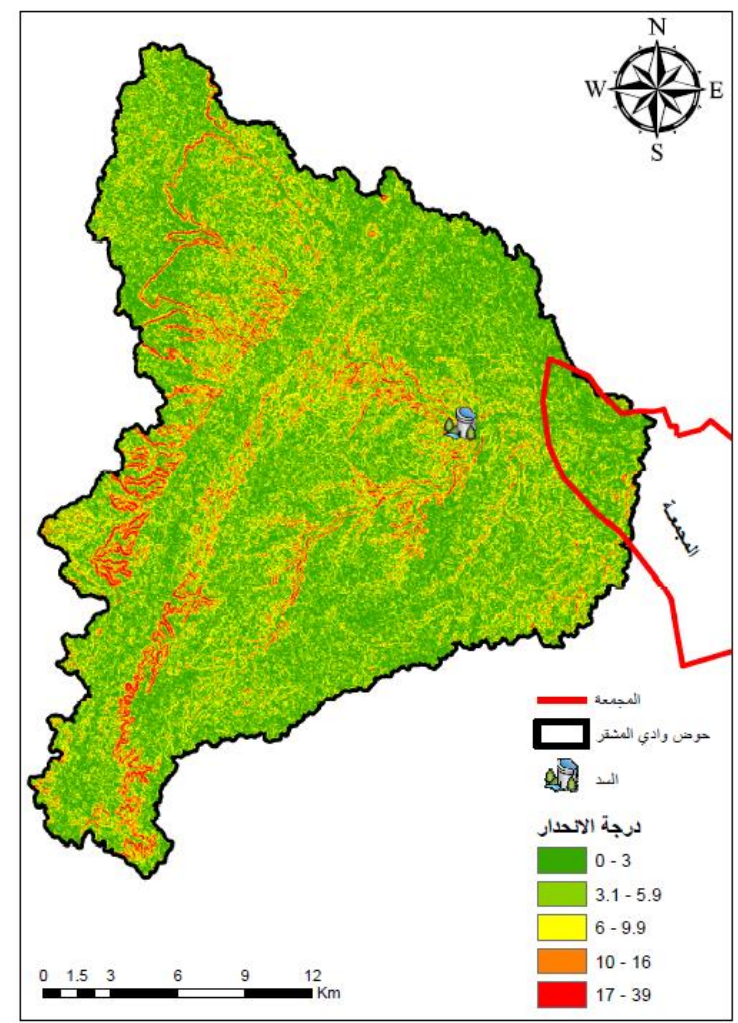

جدول 1 معدل الانحدار في حوض المشقر

\begin{tabular}{|c|c|c|c|}
\hline الالالة & النسبة من المساحة الكلية & المساحة & الاتحدار \\
\hline مستوي & $3 \%$ & 15 & $\mathbf{0}$ \\
\hline شبة مستوي خفيف جدا & $23 \%$ & 116 كم2 & $1-2$ \\
\hline انحدار خفيف & $43 \%$ & 214 & $2-5$ \\
\hline انحدار متوسط & $21 \%$ & 107 كم2 & $5-10$ \\
\hline انحدار فوق المتوسط & $5.3 \%$ & 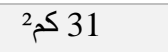 & $10-18$ \\
\hline انحدار شديد & $1.1 \%$ & 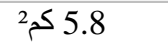 & 18-30 \\
\hline انحدار شديد جدا & $0.01 \%$ & 20.08 0.08 & 30 فا اعلى \\
\hline
\end{tabular}

- التضرس (Relief) ويرمز له (R): هو الفارق لعوامل التعرية النشطة (علاجي، • ( • ب) ويستفاد من بين اعلى وأدني نقطة ويرتبط تضرس الحوض نسبة التضرس ودرجة الانحدار الي معرفة العمليات

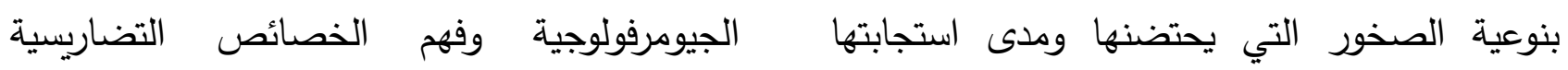




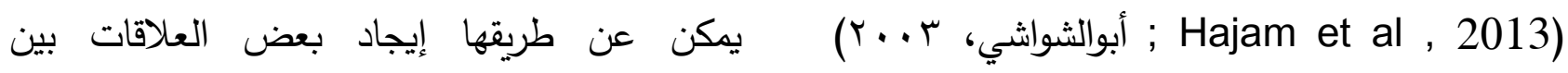

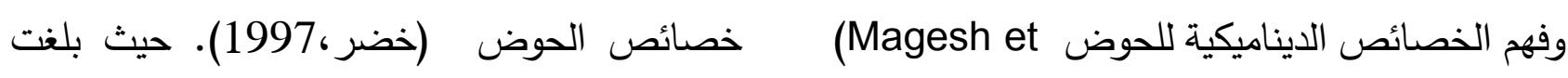
(al 2011 أي كلما صغرت مساحة الحوض كلما نسبة التضرس لحوض المشقر 0.007 وتعتبر نسبة زادت نسبة التضرس حيث تدل القيمة المرتفعة الي قليلة جدا تدل على ان نسبة التغيير منخفضة داخل

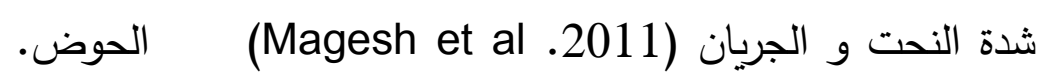
حيث توجد علاقة ارتباط بين التضرس و الصرف خصائص الثبكة المائية: والتدفق من القنوات ( 2013. Hajam et al) في ت تعتبر طرق الترتيب الهرمي لمجاري الشبكة المائية و

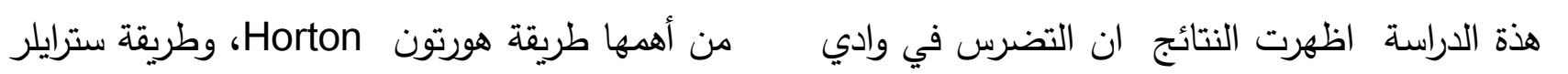

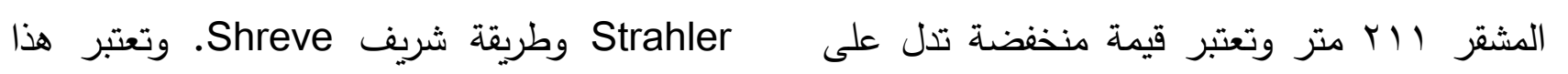
قلة التضرس وبطئ الجريان وبالتالي فان تدفق المياة الترتيب الهئي الهرمي للشبكة المائية علامة على مرحلة

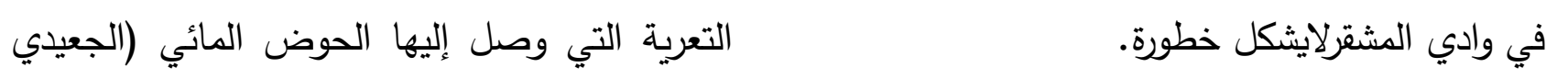

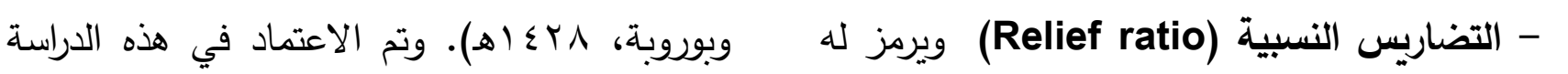

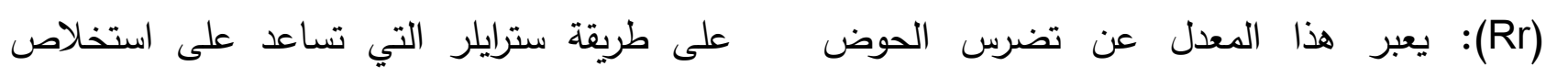

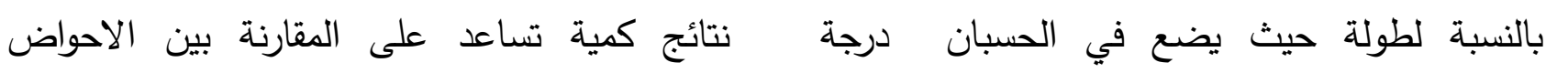

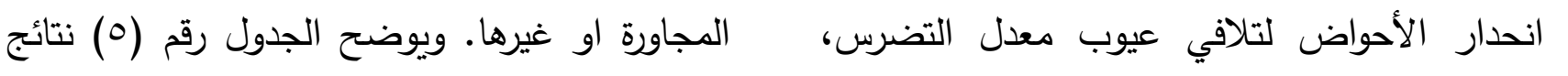

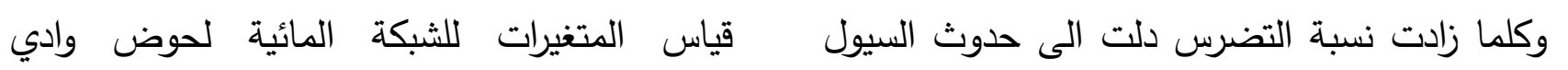
الخطرة حيث تزيد سرعة المياه وتقل الفواقد ، كما المشقروهي كالتالي:

جدول رقم (•)

نتائج الخصائص الثبكة المائية لحوض وادي المشقر

\begin{tabular}{|c|c|c|c|c|c|}
\hline نسبة التثبع & معدل طول الرتب & متوسط طول الرتبة & الطول كم & عدد المجاري & الرتبة \\
\hline & & 1,00 & 351 & 332 & الاولى \\
\hline$\{, 00$ & 1.9 & 1,9 . & 139 & 73 & الثانية \\
\hline$\{, 0\}$ & 2.4 & $\varepsilon, \gamma$ & 75 & 16 & الثالثة \\
\hline $0, r \mu$ & 1.7 & IE, rr & 43 & 3 & الرابعة \\
\hline
\end{tabular}




\begin{tabular}{|c|c|c|c|c|c|}
\hline$r$ & 2.5 & 19 & 19 & 1 & الخامسة \\
\hline & & & 627 & 425 & المجموع \\
\hline$\varepsilon, \mu_{4}$ & \multicolumn{5}{|c|}{ متوسط نسبة التشعب } \\
\hline
\end{tabular}

الشكل ؛ ـ شبكة المجاري المائية لحوض وادي المشقر

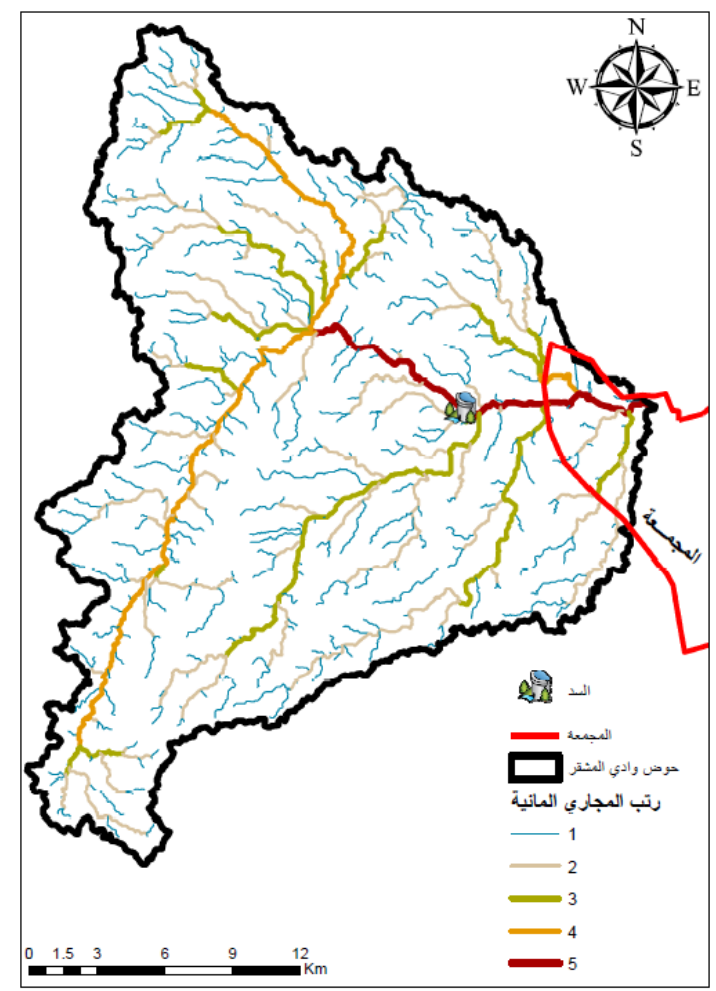

- رتب المجاري المائيه (Stream Order) ويرمز يتم الاعتماد عليه حيث يرتبط زيادة الترتيب الهرمي لها (U) ويقصد بالرتب نظام تصريف المجاري لرتب المجاري بزيادة التثرع التي من خلالها يتم بتدرج هرمي في الحوض وتعد الرتبة العنصر التصريف للمياه (Hajam et al (2013) وعند المستند اليه لمعرفة نقطة التقاء مجرين من نفس التعرف على الرتب النهرية يمكن تفسير الانحدارات الرتبة لتتكون لدينا رتبة جديدة حسب تصنيف ستيلر حيث الرتب العالية تمر على أراضي قليلة الانحدار وتعتبر الرتب الأولى هي القاعدة الاساسية اما الرتب المتوسطة تعني ان الأراضي ذات انحدار (علاجي،2010 ; ريان،2014) حيث ان تحديد متوسط اما الرتب الأولى و الثانية تدل على

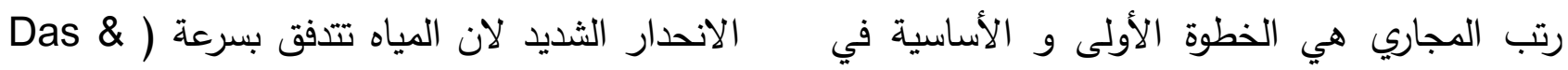
تحليل الاحواض (خضر، 1997; Hajam et al Hardeshi 2018. تشير النتائج ان وادي 2013.). وفقا لنظام Strahler1964 الذي سوف المشقر يتكون من خمسة رتب كما في الجدول (0) 
الرتب في وادي المشقر تراوح بين 1.9 الى 2.5.

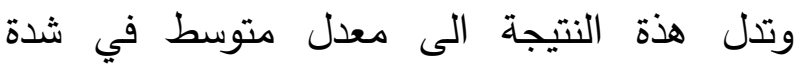
التضاريس والمنحدرات و أن الحوض في مرحلة الثباب (2013. Hajam et al (ن). نسبة التشعب Bifurcation ratio (Rb) له (Rb). يقصد بمعدل التشعب النسبة بين عدد المجاري المائية في رتبة ما وعدد المجاري في الرتبة التي تليها. حيث ان نسبة التشعب تعكس توسع المجاري المائية و التأثر الذي يصاحب سطح الحوض من الحفر الرأسي بواسطة الروافذ (Strahler 1964). تثير النتائج على ان معدل مدى التشعب لوادي المشقر ما بين ץ إلى سب,ه كما في الجدول رقم (0). أنظمة الصرف الطبيعية لديها نسبة تشعب من 3 الي 5 وتعتبر متناسقة ; Dubey et al .2015) تضاريسيأ و مناخيا علاجي، 2010 ; 2018 (Das \& Pardeshi, 2018 ومن النتائج نستطيع القول ان نسبة التشعب تعتبر

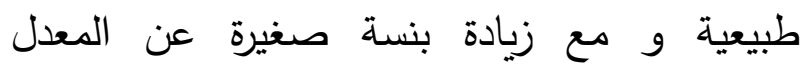
الطبيعي في الرتبة الرابعة حيث كانت نسبة التشعب بr, 0. وبلغ متوسط معدل التشعب لحوض وادي المشقر باب,ـ ممايدل على ضعف تأثير عوامل التعرية ونفاذية التركيب الصخري في حوض الوادي

.(Strahler 1964) خصائص نسيج الحوض: تتأثر شبكة التصريف في الخصائص المناخية و ولئوصن الخصائص الجيومورفولجية المتمثلة بالانحدارات
ويحتوي على 425 مجرى في مساحة تبلغ 019

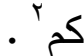
عدد الرتب Stream number ويرمز لها (Nu) الأودية ذات قدرة عالية في عملية جريان المياة، ويشكل عام يميل التصريف في المناطق الجافة إلى زيادة عدد الرتبة الأولى (خضر، يهيل عدد الرتب طرديا مع حجم الحوض و ابعاده

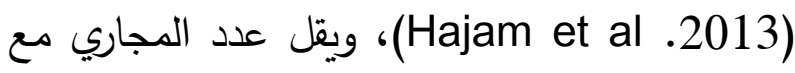
ازدياد الرتبة، حيث بلغ عدد المجاري في وادي

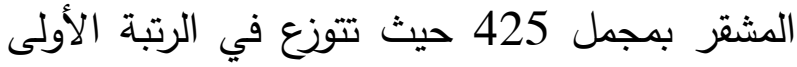
(332) اما الرتبة الثانية (73) و الرتبة الثالثة (16) و الرتبة الرابعة (3) و الرتبة الخامسة (1) وبمجموع الرعابه

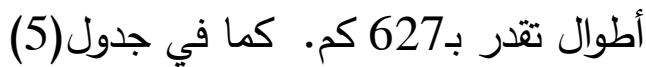
طول الرتب Stream length (km) ويرمز لها (Lu) المصب. وهناك علاقة بين أطوال الاودية والجريان المائي حيث ان زيادة متوسط الطول في الرتبة الواحدة يؤدى إلى طول رحلة الجريان. كذلك يمكن القول ان متوسط طول المجاري يزداد مع ازدياد الرتبة. وتثير النتائج الى ان مجموع أطوال الرتب

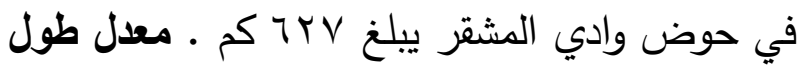
الرتب Stream length ratio (Lur) ويرمز له (Lur) الواحدة بالنسبة لطول الرتب التي يليها ( Das \& تشير النتائج ان معدل طول (Pardeshi , 2018 
والعوامل الجيولوجية و انواع الصخور. يوضح تصريف المياة في الحوض ب, اكم/كمَ وتأتي نتائج الجدول رقم (؟) نتائج قياس المتغيرات خصائص متغيرات نسيج الحوض على النحو التالي: نسيج حوض وادي المشقر والذي بلغة كثافة

جدول رقم (7)

\begin{tabular}{|c|c|c|c|}
\hline طول التدفق الارضي & معدل النسيج & تكرارية الرتب & ثثافة التصريف \\
\hline 1,7 & 0.96 & $\cdot, \wedge$ & $1, r$ \\
\hline
\end{tabular}

كفاءة شبكة التصريف في سرعة نقل المياه (خضر

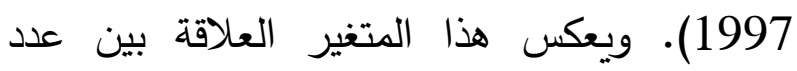
المجاري ومساحة التصريف اي كلما ازداد عدد المجاري ازداد تكرار الرتب وبتالي زادت الكثافة التصريفية (Das \& Pardeshi, 2018). تكرارية المجاري بحوض وادي المشقر منخفضة لانخفاض عدد المجاري حيث بلغ مقدار تكرار الرتب في وادي المشقر ^,، الذي يدل ضعف احتمالية حدوث

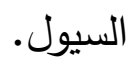

\section{Drainage Texture التصريف} ويرمز له (T): وهو مجموع عدد التدفقات على

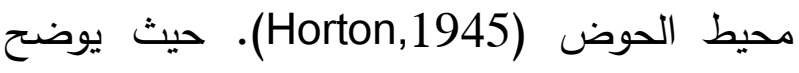
هذا المعدل مدى شدة تقطع سطح الحوض. ويتأثر بمجموعة من العوامل منها المناخ ونوع الصخور والغطاء النباتي ومرحلة التطور الجيومورفولوجي التي يمر بها الحوض ( Das \& Pardeshi, ) 2018). ولقد بلغ معدل نسيج التصريف بوادي

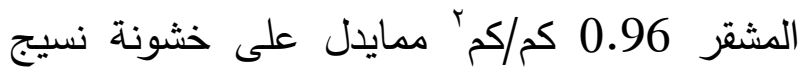
التصريف حسب تصنيف (Smith,1950) حيث
- كثافة التصريف Drainage density ويرمز له (Dd). تعد كثافة التصريف من أهم خصائص

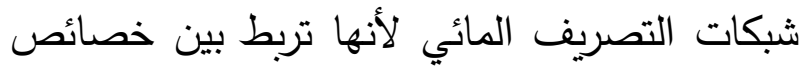

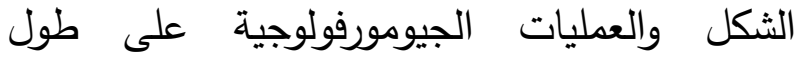
الأودية، كما أنها تعكس نسبة أطوال الأودية في وحدة مساحية محددة حيث يقصد بها نسبة انتشار الثبكة في مساحة الحوض المحددة (ابو العينين، 990 (1). . وهناك عده عوامل يمكن أن تؤثر عليها مثل نوعية الصخور والتربة والغطاء النباتي فكلما قلة النباتات زادت تعرية التربة ومن ثم زادت كثافة التصريف. وتثير نتائج التحليل إلى أنخفاض معدل كثافة التصريف في حوض وادي المشقر التي تبلغ r, اكم/كمَّ والذي يشير الى قابلية النفاذ لطبقات التركيب الصخري والذي بدورة يساهم في تقليل تأثير السيول جدول رقم (7). - تكرار الرتب Stream Frequency ويرمز لله (Fs): يعني عدد الروافد في كم² حيث يعتبر

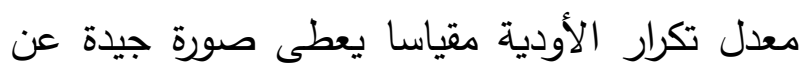
مدى شدة تقطع سطح حوض التصريف، فضلاً عن 
التصريف ومساحة الحوض و اطوالة حيث أنجز

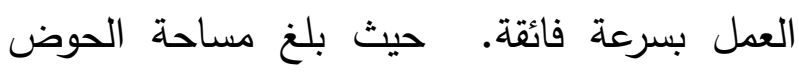

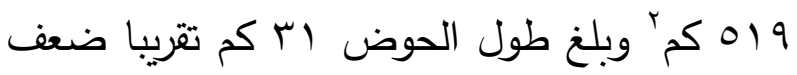
العرض الذي بلغ \, 17 كم. ومن نتائج هذة الدراسة هو معدل الاستدارة البالغ بـr, • اي شكل لايعتبر

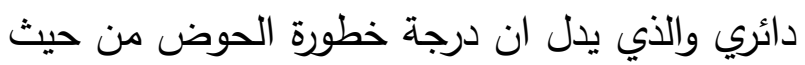

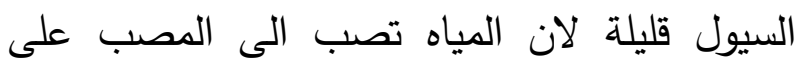

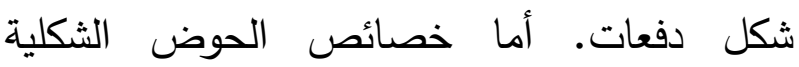

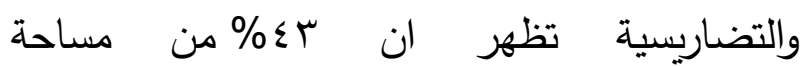
الحوض يعتبر انحدار خفيف والذ يشيربأن المياه تجري ببطيء مما يجعلها تأخذ وقت طويل في بئير الوصول الى المصب وهذا ما يثبته ايضا معامل التضرس حيث تعتبر قيمته المنخفضة مؤشر على

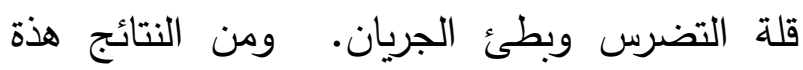
الدراسة وصف تفاصيل شبكة المجاري المائية وهي كمايلي:

- يبلغ مجموع مجاري المسيلات الصغيرة بالرتبة

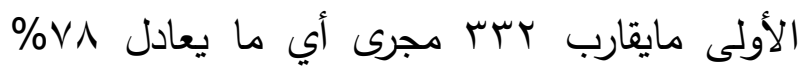
من مجموع مجاري حوض وادي المشقر .

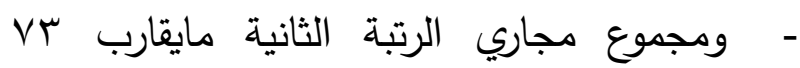

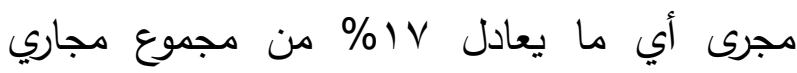
حوض وادي المشقر · مجن - مجموع مجاري الرتبة الثالثة مايقارب 17 مجرى

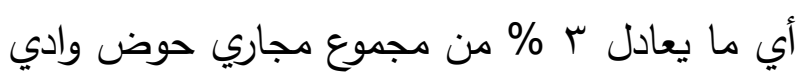

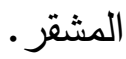

صنف نسيج التصريف الذي أقل من ؛ تحت الفئة التي لديها خشونة في التصريف. ويمكن القول ايضا

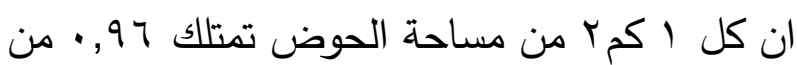
المجاري المائية لتصريف المياة. Length of طول التدفق الأرضي overland flow يعبر عن امتداد جريان الماء على سطح الحوض قبل تركزة في الروافد المائية للحوض ( Chorley, قيطن 1969). تشير النتائج الى ان طول التدفق الأرضي

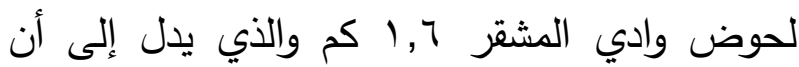
مياه الأمطار تحتاج الى وقت طويل لتكوّن مجاري

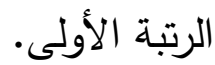
النتائج والتوصيات التوفي يوضح الشكل رقم (0) موقع وادي المشقر والتقاءة

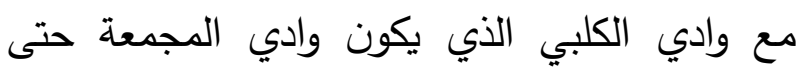
يصل الى جبال العرمة. ويوجد في وادي المشقر لئر

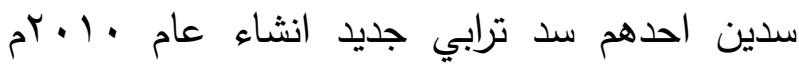
والاخر قديم يقع غرب الجديد و الذي يعتبر سد لداءيد لتخزين مياة الوادي والاستفادة منها. ولقد قدمت هذة الدراسة نموذج تطبيقي باستخدام نظم المعلومات الجغرافية و التحليل الكمي في تفسير المتغيرات المورفومترية لحوض وادي المشقر وتعد بديلا ناجحا عن الطرق القديمة التقليدية فهي اقل تكلفة واسرع في انجاز الدراسة. وكان من نتائج هذة الدراسة هو بناء قاعدة بيانات شاملة لحوض وادي المشقر لقياسات

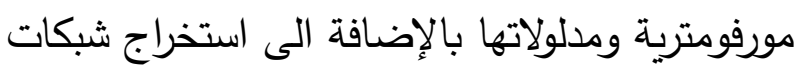


- ويبلغ مجموع مجاري الرتبة الرابعة ب مجرى أي الصخري والذي يعتبر مدلول اخر على بطئ تأثير

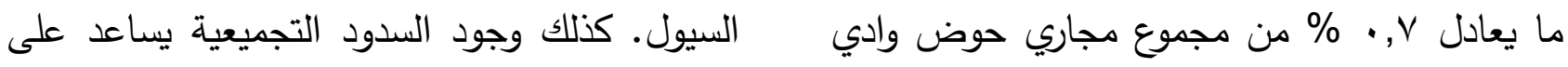

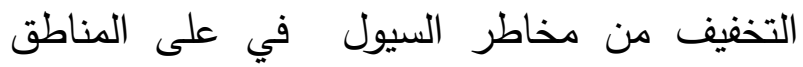

المشقر . - الم ويدل إنخفاض كثافة التصريف (r, اكم/كمr) في العمرانية المحيطة. حوض وادي المشقرعلى نفاذية طبقات التركيب الثكل ه. علاقة وادي المشقر بالاودية المجاورة

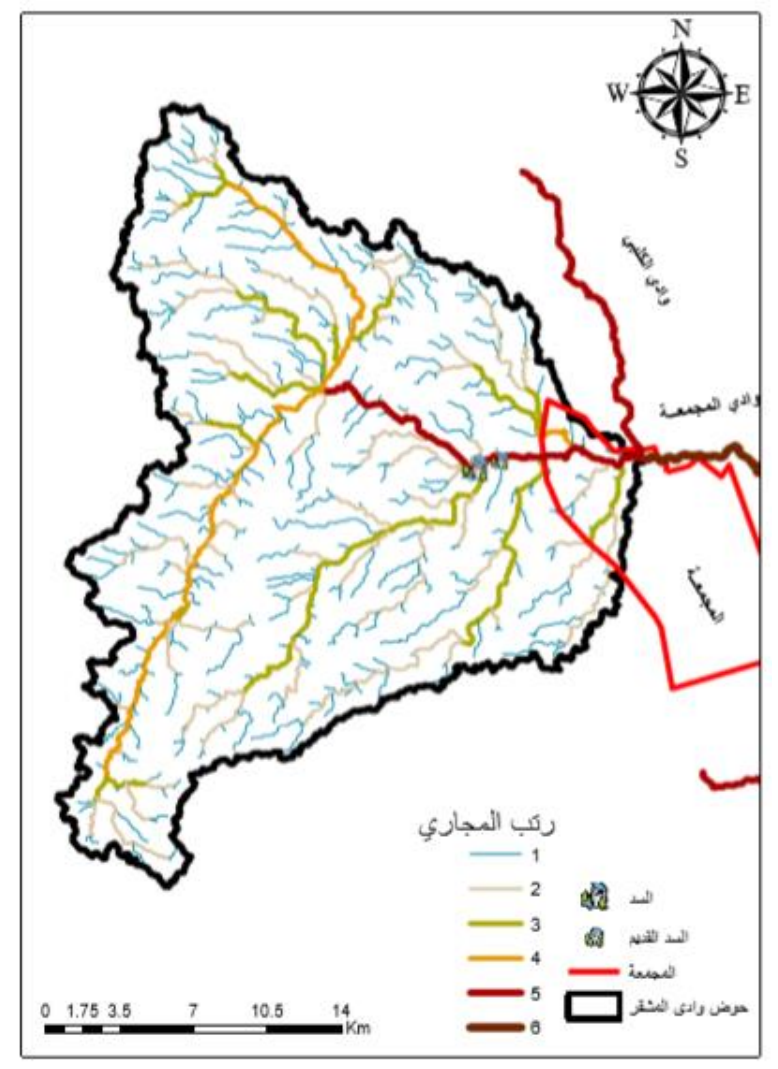

مع تطورالعلوم الجغرافية واعتمادها على نظم الارتفاعات الرقمية ويفضل ان تكون درجة الوضوح

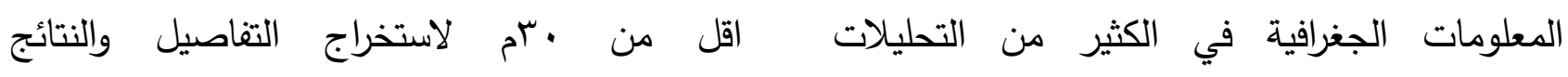

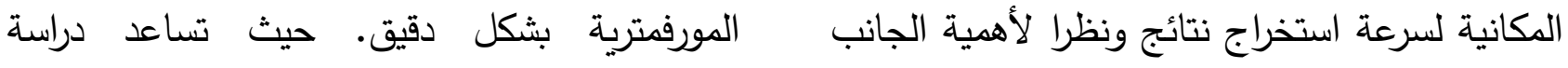

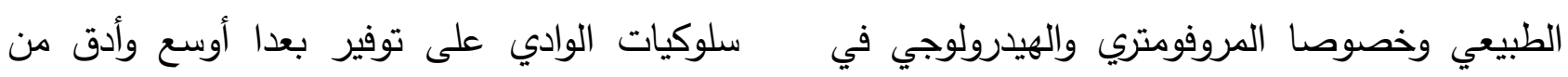

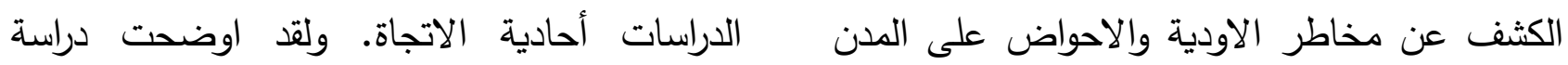

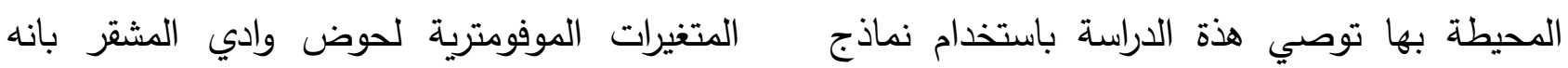


- آل سعود، مشاعل بنت محمد، (10 (Y)، تطبيقات تقنية الاستشعار عن بعد والأساليب الجيوديسية المتطورة في دراسة مورفومترية الوديان الجافة، بحوث جغرافية، الندوة السابعة، أقسام الجغرافيا بجامعات المملكة العربية السعودية، المملكة العربية السعودية. - الجعيدي، فرحان و بوروبة، محمد ( تقدير تدفق الذروة للسيول بحوض وادي العين بمحافظة الخرج في المملكة العربية السعودية، مركز البحوث، كلية الآداب، جامعة الملك سعود، عدد .$|Y|$

- الصالح، محمد بن عبدالله، (999 (م)، بعض طرق قياس المتغيرات في أحواض التصريف، بحوث جغرافية، العدد (YV)، مركز البحوث- جامعة الملك سعود، الرياض، المملكة العربية السعودية. - بلدية محافظة المجمعة، وزارة الثؤون البلدية

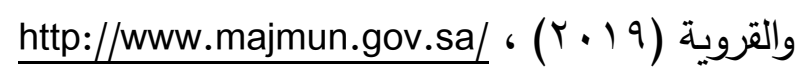
الوصول في r ا نوفمبر 9 1 ـ ب.

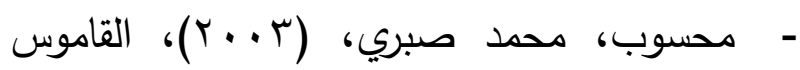
الجغرافي الجوانب الطبيعية والبيئية، الطبعة الأولى، مطبعة الاسراء، القاهرة، مصر • - عاشور، محمد. (1991) طرق التحليل المورفومتري لشبكات التصريف المائي. كلية الآداب، جامعة عين شمس، القاهرة - خضر، محمود (199V) الاخطار الجيومرفولوجية في مصر مع التركيز على السيول
لاتوجد خطورة على المناطق العمرانية المحيطة وخصوصا انه لاتوجد في اطراف الوادي عند مدخل مدينة المجمعة الى المزارع التي تستقيد من جريان السيول. ومن ذلك توصي هذة الدراسة على ان لايتم تغيير الاستعمالات للمناطق الزراعية التي يمر فيها المجرى الرئيسي للوادي الى استعمالات سكنية او تجارية. ومن التوصيات ايضا هو تدعيم هذة الدراسة بابحاث في الجواتب الهيدروجيومورفولجية التي تساعد على قياس تفاعل العوامل المختلفة وتحكمها في تشكل الوادي وحركة السيول. المراجع

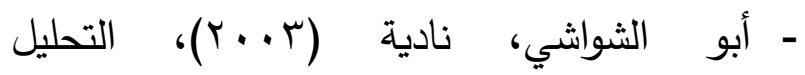
الجيومورفومتري لحوض وادي المجينين دراسة في أشكال سطح الأرض، رسالة ماجستير غير منشورة، كلية الآداب، جامعة السابع من ابريل، ليبيا.

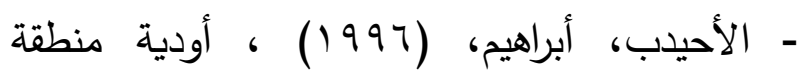
الرياض دراسة جغرافية، كلية العلوم الاجتماعية، جامعة الامام مجمد بن سعود

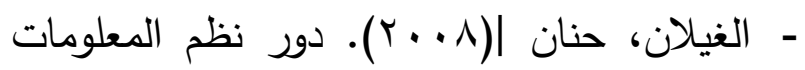
الجغرافية في دراسة الخصائص المورفومترية لحوض لوض وادي لبن، ^. ..r. رسالة ماجستير غير منشورة، كلية الآداب،جامعة الملك سعود، الرياض - أبو العينين، حسن سيد أحمد، أصول الجيومورفولجيا دراسة الأشكال التضاريسية لسطح الأرض، العدد(1) مؤسسة الثقافة الجامعية، الاسكندرية، مصر ، 1990 
منشورة، كلية العلوم الاجتماعية، جامعة الامام مجمد

$$
\text { بن سعود. }
$$

- علاجي، آمنة (• ( • ( )، تطبيق نظم المعلومات الجغرافية في بناء قاعدة بيانات للخصائص

المورفومترية ومدلولاتا الهيدرولوجية في حوض وادي يلملم، رسالة ماجستير غير منشورة ، كلية العلوم الآجتماعية، جامعة ام القرى، مكة المكرمة المملكة

$$
\text { العربية السعودية. }
$$

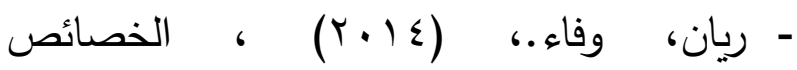
المورفومترية ل لحوض وادي الفارعة- لسطين باستخدام نظم المعلومات الجغرافية ونماذج الارتفاعات الرقمية، رسالة ماجستير غير منشورة، كلية الآداب، الجامعة الإسلامية، غزة

\section{المراجع الاجنبية}

- Burrough, P. A., (1986). Principles of geographical information systems for land resources assessment. Oxford University Press, New York, p 50

- Chorley, RJ., (1969) Water, Earth and Man: A Synthesis of Hydrology, Geomorphology and Socio-Economic Geography. London: Methuen

- Dubey, S.K., Sharma, D. and Mundetia, N., (2015) Morphometric Analysis of the Banas River Basin Using the Geographical Information System, Rajasthan, India. Hydrology. Vol. 3, No. 5, pp. 47-54.

- Horton, R. E., (1932). Drainage basin characteristics. Transactions of the American Geophysical Union, 13:350361

- Hajam RA, Hamid A, Bhat S (2013) Application of Morphometric Analysis for
في وادي النيل دراسة في الجيومرفولوجية التطبيقية، كلية الاداب، جامعة عين شمس ، القاهرة - فراج، أبوبكر، الأخطار الجيومرفولوجية في المنطقة بين بحيرة التمساح ورأس قناة السويس، رسالة ماجستير غير منشورة، كلية الآداب، جامعة القاهرة، مصر - سلوم، غزوان (Y (Y). حوض وادي القنديل (دراسة مورفومتريـة). مجلة جامعة دمشق ، المجلد م ب العدد الاول - الهدلق، محمد. (9AV) ( ). مدينة المجمعة دراسة جغرافية العمران والتخطيط. رسالة ماجستير غير

Geo-Hydrological Studies Using GeoSpatial Technology -A Case Study of Vishav Drainage Basin. Hydrol Current Res 4:157. doi: 10.4172/21577587.1000157

- Horton, R. E., (1945). Erosional development of streams and their drainage basins; Hydro-physical approach to quantitative morphology. Bulletin of the Geological Society of America, 56:275370.

- Schumm, S. A., (1956). Evolution of drainage systems and slopes in badlands at Perth Amboy, New Jersey. Bulletin of the Geological Society of America, 67: 597646

- Smith, K. G., (1950). Standards for grading texture of erosional topography. American Journal of Science, 248:655668

- Strahler, A. N., (1957). Quantitative analysis of watershed geomorphology. 


$$
\text { حمد بن أحمد التويجري و فرحان بن حسين الجعيدي ومنيره ابراهيم الخوفي }
$$

Transactions of the American Geophysical Union, 38:913-920

- Strahler, A. N., (1964). Quantitative geomorphology of drainage basins and channel networks. In: Chow Chow, V., Ed., Handbook of applied hydrology. McGraw Hill, New York, 439-476.

- Magesh NS, Chandrasekar N, Soundranayagam JP (2011) Morphometric evaluation of Papanasam and Manimuthar watersheds, parts of Western Ghats,
Tirunelveli district, Tamil Nadu, India: a GIS approach. Environ Earth Sci 64(2):373-381

- Young, A., 1972, Slopes: Edinburgh, Oliver \& Boyd. 288p

- Das, S., \& Pardeshi, S., (2018). Morphometric analysis of Vaitarna and Ulhas river basins, Maharashtra, Indiausing geospatial techniques. Applied Water Science. 8. 158. 10.1007/s13201018-0801-z. 


\title{
Wadi Al-Mashqar in Al-Majmaah: Al-Morphometric Study using Digital Elevation Model
}

\author{
Hamad Altuwaijri, \\ Associate professor, Department of Geography, College of Art, King Saud University \\ Farhan Aljuaidi, \\ Associate professor, Department of Geography, College of Art, King Saud University \\ Munerah Al Khofi, \\ Graduate student, Department of Geography, College of Art, King Saud University
}

\begin{abstract}
This study aims to determine the morphometric variables of the Wadi Al-Mashqar basin, which is one of the most important wadies in the Arriyadh region. The wadi outlet crosses through Al-Majma'ah city and confluences with the Al Kalbi wadi, which adds to the importance of the study, as over the last decades, Al-Majma'ah city has witnessed various flooding events. DEM was used as the main source data to extract morphometric characteristics. GIS was used as a tool to analyze the factors. Wadi Al-Mashqar ranks a five, according to Strahler stream order, with a total of 425 streams and total length of $627 \mathrm{~km}$. The results indicate that the limited impact of torrential rain on the urban area in Al-Majma'ah city is due to the low drainage density, which averages $1.2 \mathrm{~km} / \mathrm{km} 2$, as this leads to a slow impact of torrents. Keywords: Al-Mashqar Wadi, Al Majmaah, Morphometric Analysis, Digital Elevation Model, GIS
\end{abstract}

